\title{
OPTIMIZATION OF INTERDEPARTMENTAL INTERACTION BETWEEN FORENSIC EXPERT INSTITUTIONS OF THE MINISTRY OF JUSTICE OF UKRAINE AND THE MINISTRY OF HEALTH CARE OF UKRAINE WHILE CONDUCTING FORENSIC EXPERT ACTIVITY
}

\author{
Lozovoj A. I., Derecha L. N., Myasoedov V. V., Olkhovskiy V. A.
}

At present there is an urgent need for developing and improving normative and legal documents regulating the activity of forensic expert institutions of different departments while conducting comprehensive examinations. The needs of expert practice continuously require more thorough development for the order of conducting interdepartmental comprehensive examinations, specification and official explanation of issues connected with the ways of coordinating experts' activity, the order of their interaction at various stages of the expert study, forms of the expert panels' operation, etc. The article considers peculiarities of the activity of forensic expert institutions' within the Ministry of Justice and the Ministry of Health Care of Ukraine, methodological issues of conducting a comprehensive forensic medical, forensic criminalistic and forensic motortechnical (vehicular and traceological) examinations, the ways of optimizing the interdepartmental interaction while conducting forensic expert activity of these forensic expert institutions, legal and organizational problems of regulating their forensic expert activity. The article emphasizes the need to improve this activity by improving the legal support and efficiency of the existing system for the organization of forensic expert activity of forensic expert institutions within the the Ministry of Justice and the Ministry of Health Care of Ukraine.

Keywords: forensic expert activity, research institutions of the Ministry of Justice of Ukraine, regional forensic medical bureaus of Ministry of Health Care of Ukraine, comprehensive examinations, scientific activity.

УДК 343.98:681.5

Ю. Н. Кравченко, начальник Харьковского областного бюро судебно-медицинской экспертизы,

B. B. Canелкин, заведующий отделом Харьковского областного бюро судебно-медицинской экспертизы,

И. Ю. Сербиненко, судебно-медицинский эксперт Харьковского областного бюро судебно-медицинской экспертизы, $\boldsymbol{A}$. В. Коломийцев, ведущий научный сотрудник Харьковского НИИСЭ, кандидат технических наук

\section{ПРИМЕНЕНИЕ ИМИТАТОРА БИОЛОГИЧЕСКИХ ТКАНЕЙ ДЛЯ ДИАГНОСТИКИ СКВОЗНЫХ ОГНЕСТРЕЛЬНЫХ РАНЕНИЙ, ПРИЧИНЕННЫХ ПУЛЯМИ КАЛИБРА 5,45 мм}

На основе результатов натурных испытаний с помощью баллистического пластилина установлены особенности сквозных огнестрельных повреждений, причиненных пулями калибра 5,45 мм. Экспериментально определень 404 () Кравченко Ю. Н., Сапелкин В. В., Сербиненко И. Ю., Коломийцев А. В., 2015 
затраты кинетической энергии указанных пуль, необходимые для полного пробития блока определенной толщины с учетом их нестабильного поведения в толще преграды. Предложен расчетный метод определения скорости пуль после преодоления преграды в виде имитатора биологических тканей.

Ключевые слова: баллистический пластилин, коэффициент сопротивления вязко-упругой среды, пуля калибра 5,45 мм, раневой канал, огнестрельное ранение.

Увеличение количества огнестрельных ранений, причиненных пулями калибра 5,45 мм, привело к необходимости углубленного изучения особенностей их поведения в толще тканей биологического объекта. Основное внимание было уделено экспериментальным исследованиям с использованием в качестве имитатора биологических тканей баллистического пластилина. Это позволило не только оценить объемы причиненных повреждений, имеющих высокую степень достоверности, но и определить ряд параметров, необходимых для дальнейших расчетов по определению запреградного действия 5,45 мм пуль.

Особенностью 5,45 мм пуль промежуточных патронов калибра 5,45×39, снаряженных пулей ПС со стальным сердечником (индекс патрона 7Н6), а также пулями повышенной пробивной способности ПП с термоупрочненным стальным сердечником (индекс патрона 7Н10), является их достаточно высокая скорость. Общий вид патронов и пуль представлен на рис. 1, 2.
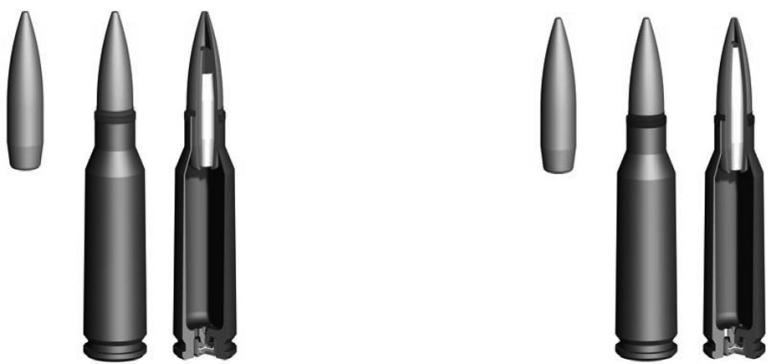

Рис. 1. Общий вид патрона $5,45 \times 39$, Рис. 2. Общий вид патрона $5,45 \times 39$, снаряженного пулей ПС (индекс 7Н6) снаряженного пулей ПП (индекс 7Н10)

В ходе проведения экспериментальных стрельб в условиях баллистической трасы было установлено, что при стрельбе из 5,45 мм автомата АКС-74У начальная скорость выстрелянных пуль составляет 741-754 м/с, а при стрельбе из 5,45 мм автомата АК-74, начальная скорость выстрелянных пуль составляет 912-925 м/с. При таких высоких скоростях в тканях биологического происхождения будут формироваться достаточно обширные зоны поражения, обусловленные гидродинамическим действием пуль. Кроме того, при попадании в вязкоупругую среду, к которой относятся и биологические ткани, из-за небольшой массы продолговатые и легкие 5,45 мм пули почти сразу теряют гироскопическую устойчивость, в результате чего они начина- 
ют совершать достаточно сложное поступательное движение с одновременным вращением вокруг одной из своих экваториальных осей. Это неизменно сказывается на характере раневого канала (рис. 3,4$)$.

В ходе экспериментов было установлено, что при похождении первичного участка длиной порядка 155-175 мм пуля, по отношению к первоначальному своему положению, разворачивается на 90, что характеризуется максимальными размерами образующейся временно-пульсирующей полости, и в последующем, разворачиваясь далее, пуля движется вперед своей хвостовой частью.

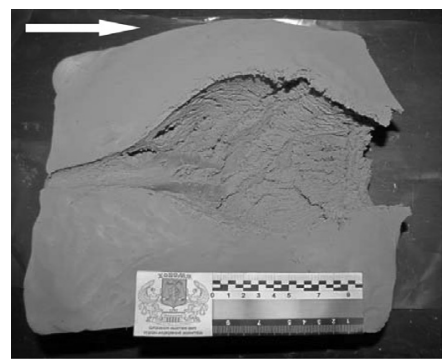

Рис. 3. Продольный разрез блока баллистического пластилина после попадания в него пули ПС патрона 7Н6 (скорость пули в момент попадания $745 \mathrm{~m} / \mathrm{c}$, направление движения показано стрелкой)

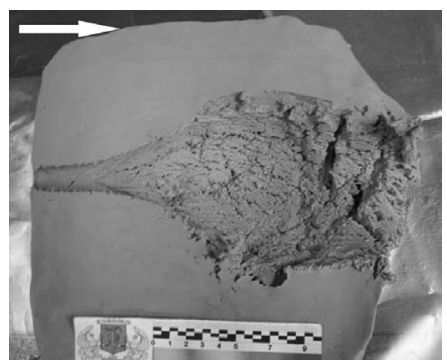

Рис. 4. Продольный разрез блока баллистического пластилина после попадания в него пули ПП патрона 7Н10 (скорость пули в момент попадания 739 м/с, направление движения показано стрелкой)

Таким образом, размеры выходного огнестрельного повреждения существенно превосходят размеры входного повреждения сквозного огнестрельного ранения (рис. 5,6 ). В ходе экспериментальных исследований было установлено, что по своему характеру повреждения, причиненные как 5,45 мм пулями ПС, так и 5,45 мм пулями ПП, практически одинаковы и не имеют ярко выраженных идентифицирующих признаков, с помощью которых возможно их дифференцировать.

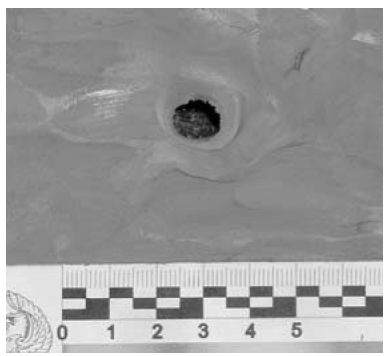

Рис. 5. Характер входного повреждения в блоке баллистического пластилина, причиненного пулей ПС

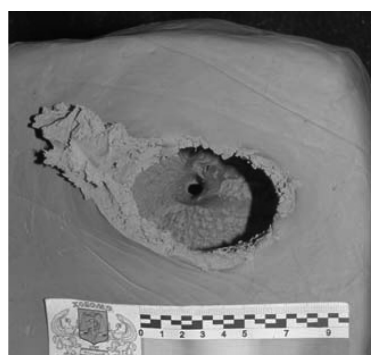

Рис. 6. Характер выходного повреждения в блоке баллистического пластилина, причиненного пулей ПС 
С целью исследования влияния толщины пробиваемой вязкоупругой преграды на устойчивость пуль проводились экспериментальные стрельбы по имитатору грудной клетки человека (рис. 7).

В ходе стрельбы было установлено, что для дестабилизации 5,45 мм пуль ПС и ПП достаточно толщины передней стенки имитатора порядка $2,0-2,5$ см. После пробития передней стенки пуля разворачивается на $180^{\circ}$ и пробитие задней стенки имитатора осуществляется уже хвостовой частью. Характер повреждений представлен на рис. 8, 9. В перевернутом положении пули также обладают достаточно высокими пробивными свойствами и способны причинить оскольчатые переломы костных тканей (рис. 9).

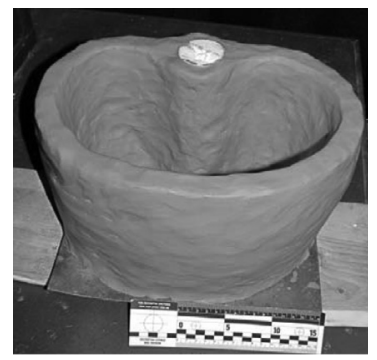

Рис. 7. Общий вид имитатора грудной клетки биологического объекта, изготовленного из баллистического пластилина и полимерного стержня

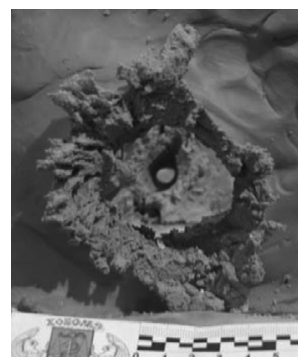

Рис. 8. Соотношение размеров входного и выходного повреждений в стенках имитатора, причиненных пулей ПП (вид со стороны задней стенки)

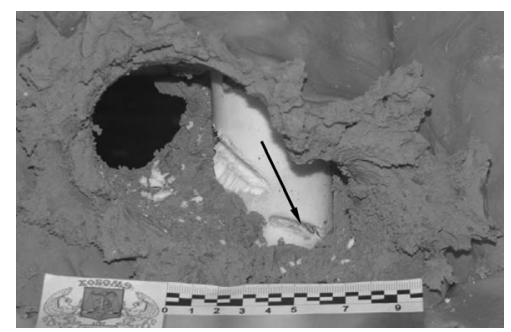

Рис. 9. Характер выходного повреждения в блоке баллистического пластилина, причиненного пулей ПП (вид изнутри блока; стрелкой указана головная часть пули)

Несомненный интерес представляют результаты исследований повреждений, причиненных пулями, в конструкцию которых были внесены изменения. Наиболее распространенным самодельным способом повышения экспансивных свойств пуль является стачивание вершины пули до обнажения сердечника. Поскольку 5,45 мм пули обладают сверхзвуковыми скоростями полета, на вершине пули происходит скачкообразное уплотнение 
воздушной среды, «закупоривая» таким образом образовавшуюся в носовой части пули полость, что незначительно сказывается на ее баллистических характеристиках. Вершины доработанных кустарным способом пуль представлены на рис. 10, 11.
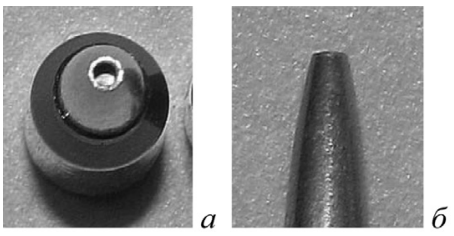

Рис. 10. Характер модифицированной пули ПС патрона 7Н6 ( $а$ - вид сверху; б-вид сбоку)
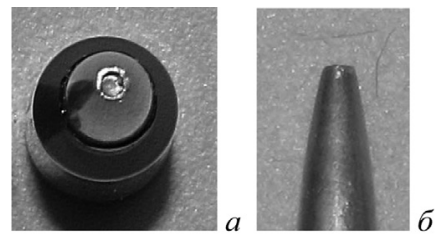

Рис. 11. Характер модифицированной пули ПП патрона 7Н10 ( $a-$ - вид сверху; б-вид сбоку)

Повреждения, причиненные модифицированными самодельным способом 5,45 мм пулями, представлены на рис. 12-15.

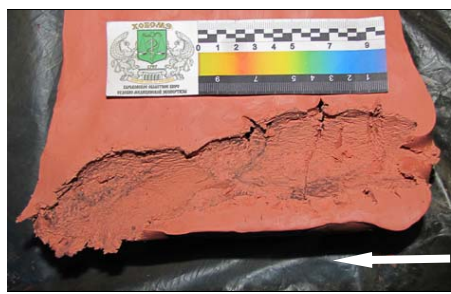

Рис. 12. Характер полости в блоке баллистического пластилина при попадании в него модифицированной 5,45 мм пули ПС (направление движения пули показано стрелкой)

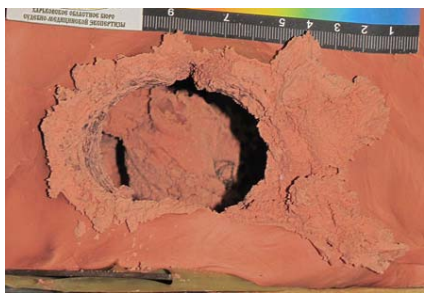

Рис. 14. Характер входного повреждения передней стенки имитатора грудной клетки при попадании в него модифицированной 5,45 мм пули ПС

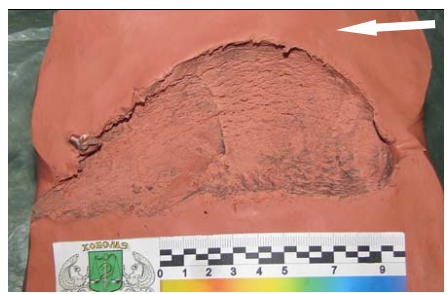

Рис. 13. Характер полости в блоке баллистического пластилина при попадании в него модифицированной 5,45 мм пули ПП (направление движения пули показано стрелкой)

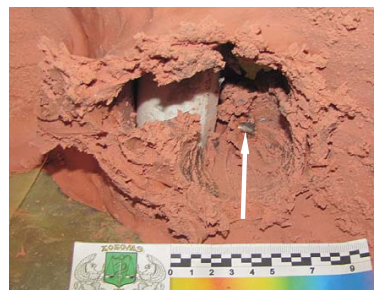

Рис. 15. Характер выходного повреждения задней стенки имитатора грудной клетки при попадании в него модифицированной 5,45 мм пули ПС (вид изнутри, стрелкой указана оболочка пули) 
Следует отметить, что не всегда попадание модифицированной пули в имитатор грудной клетки биологического объекта и в блок баллистического пластилина сопровождалось нанесением сквозного повреждения. В некоторых случаях, при попадании пули в переднюю стенку, происходила ее полная фрагментация, в результате чего повреждения задней стенки наносились как фрагментами оболочки пули, так и ее сердечником. При этом не всегда наблюдалось сквозное отверстие в задней стенке, особенно при попадании в имитатор костной ткани (рис. 16-18).

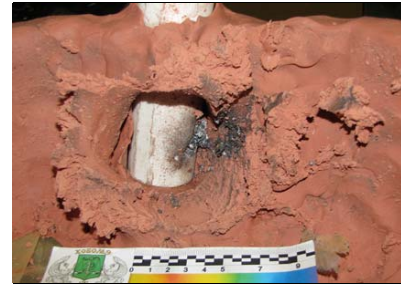

Рис. 16. Характер повреждения внутренней части задней стенки имитатора при попадании в имитатор костной ткани модифицированной 5,45 мм пули ПС

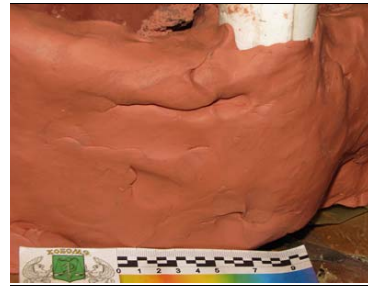

Рис. 17. Характер наружной поверхности задней стенки имитатора грудной клетки при попадании в него модифицированной 5,45 мм пули ПС (повреждение то же, что и на рис. 16)

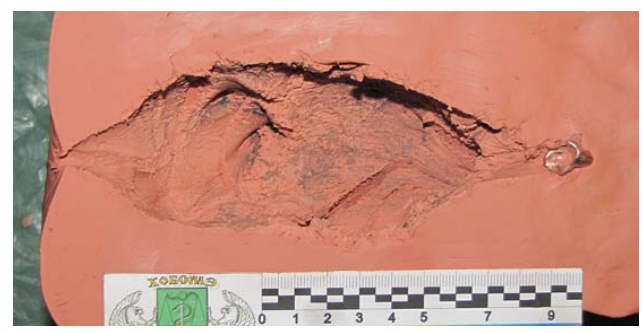

Рис. 18. Характер канала повреждения внутри блока баллистического пластилина при попадании в него модифицированной 5,45 мм пули ПС

Модифицированные таким образом 5,45 мм пули ПС и ПП обладают очень высоким останавливающим действием, а наносимые ими ранения значительной степенью тяжести и в большинстве случаев могут привести к летальному исходу. Кроме того, из-за фрагментирования причиненное повреждение характеризуется значительным количеством боковых каналов, отходящих от основного, образованного сердечником. Фрагменты пуль после попадания в блок баллистического пластилина представлены на рис. 19, 20. 


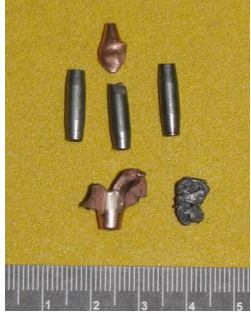

Рис. 19. Фрагменты 5,45 мм модифицированной пули ПС после попадания в имитатор грудной клетки

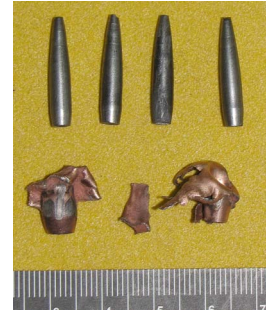

Рис. 20. Фрагменты 5,45 мм модифицированной пули ПП после попадания в имитатор грудной клетки

Входное повреждение характеризуется локализацией вокруг него значительного количества свинца от рубашки пули, который возгоняется в результате удара о преграду, что является одним из основных диагностирующих признаков.

Следует отметить, что нестабильное поведение 5,45 мм пуль ПС и ПП в толще вязкоупругой среды обусловлено тем, что центр давления, к которому прилагается результирующая сила сопротивления среды, расположен впереди центра масс пули. При движении в воздушной среде отклонения от действия этой силы компенсируются очень высокой скоростью вращения пули вокруг свой продольной оси и за счет гироскопического эффекта пуля на траектории остается стабильной. При попадании в более плотную среду сила сопротивления резко увеличивается, что приводит к образованию опрокидывающего момента, обусловленного относительно большим расстоянием между центром давления и центром масс пули. В результате действия этого момента пуля начинает «кувыркаться».

При исследовании сквозных огнестрельных ранений, причиненных 5,45 мм пулями ПС и ПП, особый интерес представляет их запреградное действие, характеризующееся остаточной величиной кинетической энергии. В ходе проведенных ранее исследований было установлено, что в подавляющем большинстве случаев, после преодоления преграды (в зависимости от ее толщины) пуля начинает двигаться вперед либо боковой частью, либо хвостовой, потеряв гироскопическую устойчивость. Таким образом, использование расчетных методов определения величины остаточной кинетической энергии пуль после преодоления преграды в виде вязкоупругой среды и величины потерь кинетической энергии существенно затрудняется из-за отсутствия данных о коэффициенте сопротивления пуль в такой среде с учетом их нестабильного поведения. Для оценки потерь 5,45 мм пулями кинетической энергии и определения соответствующего коэффициента сопротивления среды проводились экспериментальные стрельбы по блоку баллистического пластилина, установленного между двумя оптоэлектронными измерительными комплексами ИБХ-731 (рис. 21, 22). Стрельба велась из автомата АК74 с дистанции 5,0 м тремя сериями по 5 патронов, снаряженных пулей ПС. Результаты стрельб представлены в табл. 1. 


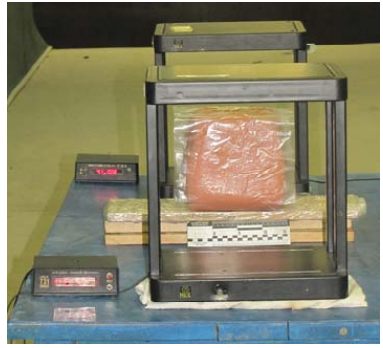

Рис. 21. Экспериментальная установка (вид спереди)

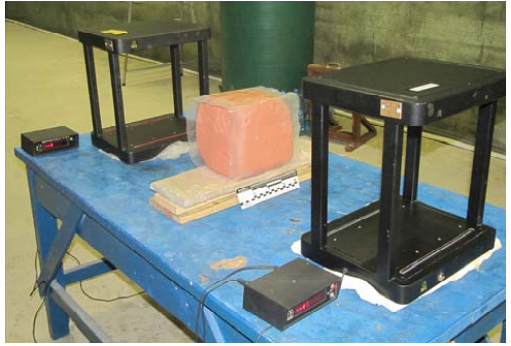

Рис. 22. Экспериментальная установка (вид сбоку)

Проведенные исследования позволили определить скорость пуль в момент попадания в имитатор, а также ее конечную скорость после преодоления преграды с учетом нестабильного поведения пули в толще среды.

Т а бл и ц а 1

Усредненные значения величин скорости 5,45 мм пуль в момент попадания в блок баллистического пластилина и после его пробития

\begin{tabular}{|c|c|c|c|}
\hline $\begin{array}{c}\text { № } \\
\text { серии }\end{array}$ & $\begin{array}{c}\text { Толщина } \\
\text { блока, мм }\end{array}$ & $\begin{array}{c}\text { Усредненная скорость } \\
\text { пули в момент попадания } \\
\text { в блок, м/с }\end{array}$ & $\begin{array}{c}\text { Усредненная скорость } \\
\text { пули после пробития } \\
\text { блока, м/с }\end{array}$ \\
\hline 1 & 165 & 915 & 359 \\
\hline 2 & 180 & 919 & 317 \\
\hline 3 & 240 & 921 & 184 \\
\hline
\end{tabular}

Расстояние между измерительными оптоэлектронными комплексами составляло 1,0 м. В ходе экспериментов было установлено, что с увеличением толщины блока происходит существенное искривление траектории движения пули в толще преграды, что резко повышает вероятность повреждения измерительного оборудования. В результате этого толщина блока было ограничена величиной 240 мм.

Для определения коэффициента сопротивления вязкоупругой среды использовалось эмпирическое выражение: ${ }^{1}$

$$
C_{R}=\frac{2 m}{\rho S_{0} x} \ln \frac{V_{c}}{V_{r}},
$$

где $C_{R}$ - коэффициент сопротивления среды для исследуемой пули; $m$ - масса пули, г; $S_{0}$ - площадь поперечного сечения пули, см² $^{2} x$ - длина раневого канала

1 См.: Озереияковский Л. Б. Раневая баллистика. История и современное состояние огнестрельного оружия и средств индивидуальной бронезащиты / Л. Б. Озерецковский, Е. К. Гуманенко, В. В. Бояринцев. - СПб. : Журнал «Калашников», 2006. - 374 с. 


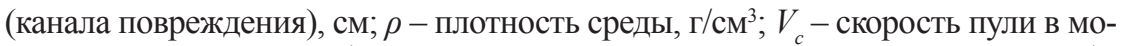
мент встречи с целью, м/с; $V_{r}$ - скорость пули после преодоления преграды, м/с.

В результате применения эмпирического выражения (1) с учетом полученных экспериментальных данных было установлено, что для 5,45 мм пуль ПС величина коэффициента сопротивления вязкоупругой среды имитатора тканей биологического объекта составляет $C_{R}=1,488-1,760$. Увеличение коэффициента сопротивления среды связано с тем, что с увеличением толщины преграды существенно изменяется положение пули в преграде и, соответственно, увеличивается контактная площадь и сопротивление среды. Для расчетов возможно использовать усредненное значение коэффициента сопротивления $C_{R}=1,6$.

Ввиду идентичности формы и размеров пуль ПС и ПП патронов с индексом 7Н6 и 7Н10 для расчетов их характеристик можно использовать экспериментально установленные значения коэффициентов сопротивления вязкоупругой среды (биологических тканей).

Применение этого значения коэффициента сопротивления позволяет по эмпирическому выражению (2) 1 определить скорость пули после пробития ею вязкоупругой преграды соответствующей толщины:

$$
V_{r}=V_{c} e-\frac{C_{R} \rho S_{0}}{2 m} x
$$

Результаты расчетов величины скорости пули после преодоления преграды соответствующей толщины, а также величины потерь кинетической энергии представлены в таблицах 2, 3 .

Т а б ли ц а 2

Расчетные значения величин скорости 5,45 мм пули ПС после преодоления преграды и затраты пули кинетической энергии на пробитие преграды при скорости контакта с целью 912 и 925 м/с

\begin{tabular}{|c|c|c|c|c|c|c|}
\hline № & $V_{c}, \mathbf{M} / \mathbf{c}$ & $T, \mathbf{c м}$ & $V_{r}, \mathbf{M} / \mathbf{c}$ & $E_{c}$, Дж & $E_{r}$, Дж & $\Delta E$, Дж \\
\hline 1 & \multirow{5}{*}{912} & 10 & 495,59 & \multirow{5}{*}{1422,28} & 419,99 & 1002,29 \\
\hline 2 & & 15 & 365,33 & & 228,23 & 1194,05 \\
\hline 3 & & 20 & 269,31 & & 124,02 & 1298,26 \\
\hline 4 & & 25 & 198,52 & & 67,39 & 1354,89 \\
\hline 5 & & 30 & 146,35 & & 36,62 & 1385,66 \\
\hline 6 & \multirow{5}{*}{925} & 10 & 502,65 & \multirow{5}{*}{1463,12} & 432,05 & 1031,07 \\
\hline 7 & & 15 & 370,54 & & 234,78 & 1228,34 \\
\hline 8 & & 20 & 273,15 & & 127,58 & 1335,54 \\
\hline 9 & & 25 & 201,35 & & 69,33 & 1393,79 \\
\hline 10 & & 30 & 148,43 & & 37,67 & 1425,44 \\
\hline
\end{tabular}

${ }^{1}$ См.: Озерециковский Л. Б., Гуманенко Е. К., В. В. Бояриниев. Указ. работа. 
Т а бл и ц а 3

Расчетные значения величин скорости 5,45 мм пули ПС после преодоления преграды и затраты пули кинетической энергии на пробитие преграды при скорости контакта с целью 741 и 754 м/с

\begin{tabular}{|c|c|c|c|c|c|c|}
\hline № & $V_{c,}, \mathbf{M} / \mathbf{c}$ & $T$, см & $V_{r}, \mathbf{M} / \mathbf{c}$ & $E$, , Дж & $E_{r}$, Дж & $\Delta E$, Дж \\
\hline 1 & \multirow{5}{*}{741} & 10 & 402,67 & \multirow{5}{*}{938,93} & 277,26 & 661,67 \\
\hline 2 & & 15 & 296,83 & & 150,67 & 788,26 \\
\hline 3 & & 20 & 218,81 & & 81,87 & 857,05 \\
\hline 4 & & 25 & 161,30 & & 44,49 & 894,44 \\
\hline 5 & & 30 & 118,91 & & 24,18 & 914,75 \\
\hline 6 & \multirow{5}{*}{754} & 10 & 409,73 & \multirow{5}{*}{972,16} & 287,07 & 685,09 \\
\hline 7 & & 15 & 302,04 & & 156,00 & 816,16 \\
\hline 8 & & 20 & 222,65 & & 84,77 & 887,39 \\
\hline 9 & & 25 & 164,13 & & 46,07 & 926,10 \\
\hline 10 & & 30 & 120,99 & & 25,03 & 947,13 \\
\hline
\end{tabular}

где $T$ - толщина преграды (длина канала повреждения); $E_{c}$ - величина кинетической энергии пули до встречи с целью; $E_{r}-$ величина кинетической энергии пули после пробития преграды; $\Delta E$ - величина потерь кинетической энергии пули на пробитие преграды определенной толщины.

Полученные данные удовлетворительно коррелируются с результатами натурных испытаний, что позволяет их использовать для решения практических задач комплексных судебно-медицинских и судебно-баллистических исследований. Таким образом, зная длину раневого канала, причиненного 5,45 мм пулей и используя для расчетов полученные значения коэффициента сопротивления среды, можно определить затраты кинетической энергии пули на преодоление преграды, а также ее баллистические характеристики.

\section{ЗАСТОСУВАННЯ ІМІТАТОРА БІОЛОГІЧНИХ ТКАНИН ДЛЯ ДІАГНОСТУВАННЯ НАСКРІЗНИХ ВОГНЕПАЛЬНИХ ПОРАНЕНЬ, СПРИЧИНЕНИХ КУЛЯМИ КАЛІБРУ 5,45 мм}

Кравченко Ю. М., Сапєлкін В. В., Сербіненко І. Ю., Коломійцев О. В.

На основі результатів натурних випробувань за допомогою балістичного пластиліну встановлено особливості наскрізних вогнепальних пошкоджень, заподіяних кулями калібру 5,45 мм. Експериментально визначені витрати кінетичної енергї зазначених куль, необхідні для повного пробиття блоку певної товщчни з урахуванням їх нестабільної поведінки в товщі перешкоди. Запропоновано розрахунковий метод визначення швидкості куль після подолання перешкоди у вигляді імітатора біологічних тканин.

Ключові слова: балістичний пластилін, коефіuуінт опору середовища, куля калібру 5,45 мм, рановий канал, вогнепальне поранення. 


\title{
THE APPLICATION OF BIOLOGICAL TISSUE SIMULATOR TO DIAGNOSE PERFORATING GUNSHOT WOUNDS CAUSED BY 5.45 mm CALIBER BULLETS
}

\author{
Kravchenko Y. N., Sapelkin V. V., Serbinenko I. Y., Kolomijtsev A. V.
}

The study and diagnosis of perforating gunshot wounds, especially those that are caused by $5.45 \mathrm{~mm}$ caliber bullets are connected with certain difficulties due to the instable behavior of these bullets in biological tissues (viscoelastic environment). With regard to that and based on the natural tests with the help of ballistic plasticine, the article establishes the peculiarities of perforating gunshot injuries caused by the abovementioned bullets. The natural tests also allowed to determine the influence of the changes made in the bullet structure in order to increase its expansion properties. In addition, the experiments determined the amount of kinetic energy of $5.45 \mathrm{~mm}$ bullets in order to perforate a block of ballistic plasticine of the respective width, it allowed to determine the resistance coefficient of the viscoelastic environment with regard to the unstable behavior of the bullet inside the obstacle. The article suggests a method to determine the speed of the bullet after it leaves the obstacle in the form of a simulator of biological tissues, it allows to determine the ballistic properties of $5.45 \mathrm{~mm}$ bullets before and after its contact with the obstacle.

Keywords: ballistic plasticine, coefficient of the viscoelastic environment, $5.45 \mathrm{~mm}$ caliber bullets, wound tract, gunshot wounds. 